\title{
Less contentious, more bureaucratic
}

Four or five years ago there were clamorous objections concerning the negative effects of the European Working Time Directive (EWTD) on work patterns and training. The requirement to move to shift working to accommodate mandatory rest periods, the loss of continuity of patient care, and a reduction in training opportunities as the 'firm' system disintegrated, were all identified as undesirable consequences of the directive. Eventually, in October 2013, Professor Norman Williams, president of the Royal College of Surgeons, was asked by the secretary of state for health to chair an independent taskforce on the implementation of the EWTD and its impact on the NHS and health professionals. With commendable speed the final report of the taskforce was delivered on 3 April 2014. ${ }^{1}$

In essence the report might be summarised as confirming that compliance with EWTD had very mixed effects, but the future lies in working with it. It is neither possible nor desirable to go back in time to the impossibly long hours of which senior consultants like to reminisce (the wards of course were much calmer then). Indeed, in respect of the work-life balance of trainees, implementation has paid dividends. The RCP's survey, quoted in the their evidence to the task force, shows that trainees believe that EWTD has brought about a marked improvement in their work-life balance, with 54\% in 2012-13 believing that this had improved as a result of the Directive, compared to a third in $2009-10 .^{2}$ At the same time the task force report corroborated the difficulties that implementation had caused with training in some specialties, including acute medicine as well as the surgical specialties. Indeed the RCP's survey confirms that majority of trainees across all the RCP's specialties continue to think there has been a sustained deterioration in the quality of both patient care and training, and that perception has not changed significantly over the last four years. ${ }^{2}$

The secretary of state accepted all the recommendations of the task force ${ }^{3}$ - though it must be said many of them are in the 'further work is needed' category. Many were very straightforward: review best practice in the design of working practices, address specific challenges faced by some specialties, and seek to mitigate the effects of the European Court judgements which tighten the straitjacket of the EWTD with definitions of rest periods and so on. The most far-reaching may well be 'the possibility of creating protected education and training time for junior doctors should be explored'.

As the letter to the secretary of state accompanying the report acknowledges, trainee groups and professional societies have lobbied for this for some time, to avoid the ever-present clinical imperatives from squeezing out formal training. However, the means suggested for protecting education and teaching time raises major issues. The task force suggests the separation of the protected hours spent in training and learning from those which are considered as 'work' by the working time directive.
The suggested pathway to achieving this is the creation of separate specialty-specific educational grants to pay for the protected time spent in training and education.

That will clearly raise concerns in respect of junior doctors' incomes, if remuneration of such time lies outside junior doctors' pay arrangements; organisations such as the BMA will surely keep developments keenly under review as the impact of the task force report on contractual areas works through. It also raises anxieties that if training is a separately organised and remunerated activity, whose hours fall outside the control of the EWTD and UK working time regulations, there may be a reversal of the reduction in weekly hours due that was so clearly welcomed by trainees when those directives were implemented.

Implementation of the task force recommendations is likely to accelerate another process. If training is funded via a separate income stream, the quality control of that process will undoubtedly come under greater scrutiny. The General Medical Council (GMC) has already initiated moves to regulate trainers in medical schools and hospitals, as it does already for GP trainers. ${ }^{4}$ Currently the council lacks the legal powers to approve trainers, but anticipates that by 2016 it will have acquired those powers. It is in the meanwhile encouraging recognition of trainers. Such recognition and eventually approval will be required, not by everyone who is involved in teaching, but by doctors with significant involvement in undergraduate and postgraduate training. In the hospital service this means named educational supervisors (responsible for the overall supervision of doctors in training and their progression during placements) and clinical supervisors (responsible for overseeing the work of a trainee throughout a placement). Thus this involves a huge number of consultants. Pending the GMC's acquisition of legal powers, the processes for obtaining recognition are defined by the local educational organiser - for postgraduate trainers generally the local education and training board or postgraduate deanery - and the exercise is in train. The Academy of Medical Educators has drawn up a guide to obtaining recognition as a trainer, attempting to reassure its readers that this process is a fairly simple add-on to the processes of revalidation and appraisal. ${ }^{5}$ Trainers will hope that is an accurate prediction.

\section{References}

1 Royal College of Surgeons. The implementation of the working time directive, and its impact on the NHS and health professionals: Report of the independent working time regulations taskforce to the department of health. RCS, 2014. Available online at www.rcseng.ac.uk/ policy/working-time-directive-taskforce [Accessed 1 October 2014].

2 Royal College of Physicians. Response to call for evidence on implementation of the European Working Time Directive. Available online at www.rcseng.ac.uk/policy/documents/RCPresponseonim plementingEWTD.pdf [Accessed 1 October 2014]. 
3 Department of Health. The Government's response to the review of the impact and implementation of the European Working Time Directive on the NHS. DOH, 2014. Available online at www.gov.uk/ government/news/more-flexibility-for-nhs-doctors-undereuropean-working-time-directive [Accessed 1 October 2014].

4 General Medical Council. Recognition and approval of trainers. Available online at www.gmc-uk.org/education/10264.asp [Accessed 1 October 2014].
5 Browne J, Bullock A, Gallen D on behalf of the Academy of Medical Educators. The essential user guide to recognition of training in secondary care 2013. Available online at www.medicaleducators.org/ index.cfm/resources1/ [Accessed 1 October 2014].

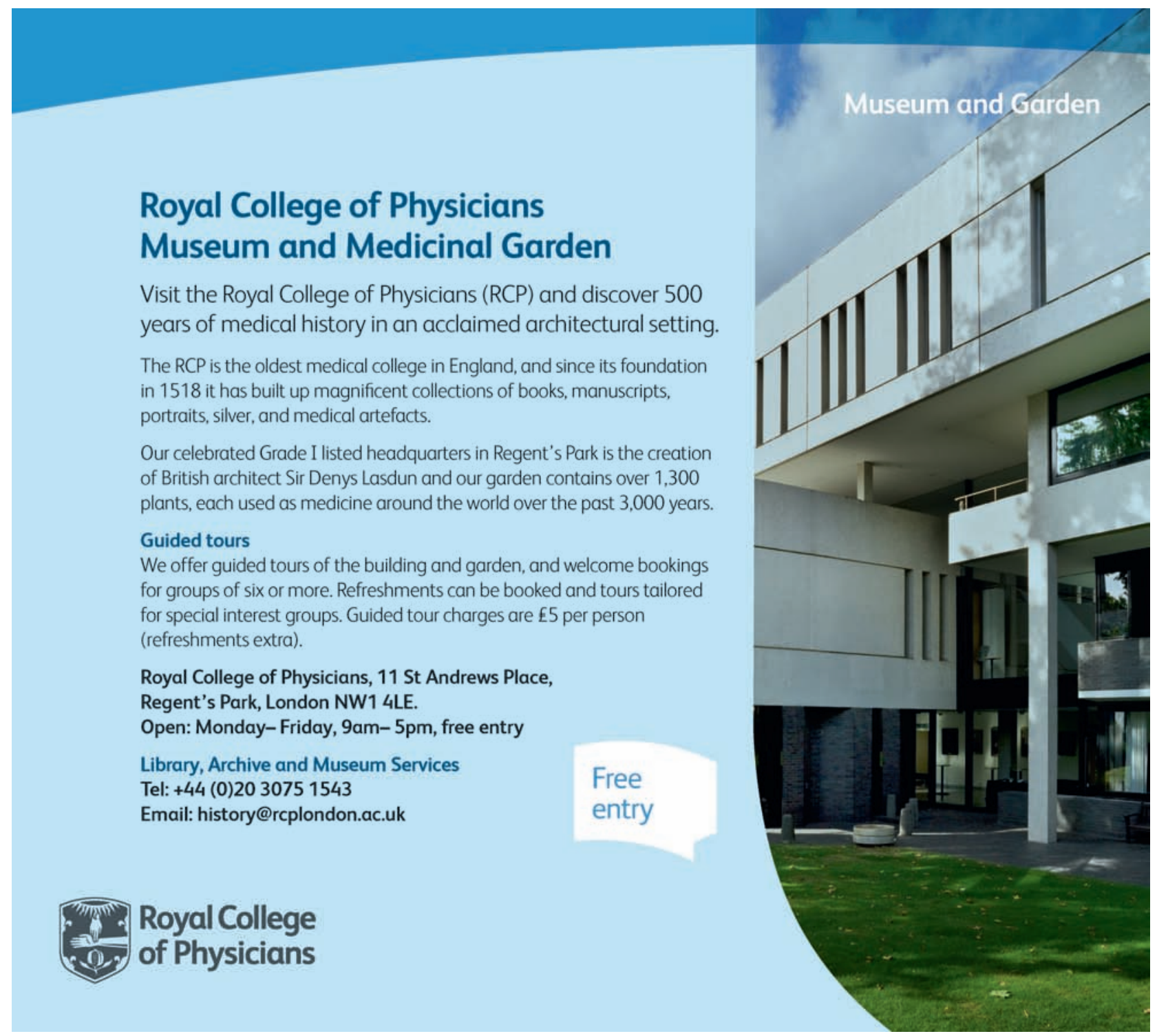

